\title{
Towards understanding interactions between Sustainable Development Goals: the role of environment-human linkages
}

\author{
Jörn P. W. Scharlemann ${ }^{1,2}\left(\right.$ Rebecca C. Brock $^{2} \cdot$ Nicholas Balfour $^{1}\left(\right.$ R $^{\circ} \cdot$ Claire Brown $^{2}\left(\mathbb{D} \cdot\right.$ Neil D. Burgess $^{2,3}$. \\ Miriam K. Guth ${ }^{2}$. Daniel J. Ingram ${ }^{1,4} \cdot$ Richard Lane $^{1,5,6}$ - Juliette G. C. Martin ${ }^{2,7}$. Sylvia Wicander ${ }^{2}$. \\ Valerie Kapos ${ }^{2}$ (D)
}

Received: 30 August 2019 / Accepted: 16 March 2020 / Published online: 1 April 2020

(c) The Author(s) 2020

\begin{abstract}
Only 10 years remain to achieve all Sustainable Development Goals (SDGs) globally, so there is a growing need to increase the effectiveness and efficiency of action by targeting multiple SDGs. The SDGs were conceived as an 'indivisible whole', but interactions between SDGs need to be better understood. Several previous assessments have begun to explore interactions including synergies and possible conflicts between the SDGs, and differ widely in their conclusions. Although some highlight the role of the more environmentally-focused SDGs in underpinning sustainable development, none specifically focuses on environment-human linkages. Assessing interactions between SDGs, and the influence of environment on them can make an important contribution to informing decisions in 2020 and beyond. Here, we review previous assessments of interactions among SDGs, apply an influence matrix to assess pairwise interactions between all SDGs, and show how viewing these from the perspective of environment-human linkages can influence the outcome. Environment, and environment-human linkages, influence most interactions between SDGs. Our action-focused assessment enables decision makers to focus environmental management to have the greatest impacts and to identify opportunities to build on synergies and reduce trade-offs between particular SDGs. It may enable sectoral decision makers to seek support from environment managers for achieving their goals. We explore cross-cutting issues and the relevance and potential application of our approach in supporting decision making for progress to achieve the SDGs.
\end{abstract}

Keywords 2030 Agenda $\cdot$ Synergies $\cdot$ Trade-offs $\cdot$ Perspective $\cdot$ Influence matrix

Handled by Joseph Alcamo, University of Sussex, United

Kingdom.

Jörn P. W. Scharlemann

J.Scharlemann@sussex.ac.uk

1 School of Life Sciences, University of Sussex, Brighton BN1 9QG, UK

2 United Nations Environment Programme World Conservation Monitoring Centre, 219 Huntingdon Road, Cambridge CB3 0DL, UK

3 Globe Institute, University of Copenhagen, Copenhagen, Denmark

4 Present Address: African Forest Ecology Group, Biological and Environmental Sciences, University of Stirling, Stirling FK9 4LA, UK
5 Present Address: Environmental Governance Group, Copernicus Institute of Sustainable Development, Utrecht University, 3584 CB Utrecht, The Netherlands

6 Present Address: Centre for Global Political Economy, University of Sussex, Brighton BN1 9RH, UK

7 Present Address: International Institute for Applied Systems Analysis (IIASA), Risk and Resilience Program (RISK), Schlossplatz 1, 2361 Laxenburg, Austria 


\section{Introduction}

In 2015, the 193 countries of the United Nations (UN) General Assembly adopted the 2030 Development Agenda, which commits all countries and stakeholders to act in collaborative partnership to end poverty and hunger, and to protect the planet from degradation, so that it can support the needs of present and future generations (UN 2015). At its core, the 2030 Agenda includes 17 Sustainable Development Goals (SDGs) comprising 169 targets to be achieved by 2030. These SDGs, which took effect in January 2016, are applicable to all countries, regardless of development status. They build on the UN's Millennium Development Goals (MDGs) (UN 2000), drawing on several years of multi-stakeholder consultations, including with the private sector, and intergovernmental negotiations (Tosun and Leininger 2017), and integrate targets from other conventions, such as the UN Convention on Biological Diversity (CBD) Aichi Biodiversity Targets (CBD 2010).

The 17 SDGs, and their targets, present a new and coherent way of thinking about diverse issues related to development, such as hunger, gender and climate change, and were conceived as "integrated and indivisible and balance the three dimensions of sustainable development: the economic, social and environmental" (UN 2015). Economic, social and environmental targets are intertwined in the unified framework of 17 SDGs, forming an 'indivisible whole' (Griggs et al. 2013; Nilsson et al. 2016). Implicit in the SDGs logic is that the goals, and targets, relate to and depend on each other-but views on exactly how are evolving (Nilsson et al. 2016).

The aim of the SDGs was to stimulate action over the coming 15 years in areas of critical importance for humanity and the planet (UN 2015). Progress towards the SDGs depends on action by national governments and a wide range of actors, including the private sector, civil society organisations and millions of individuals. Progress in implementing the 2030 Agenda is tracked through voluntary reviews, which address subsets of the SDGs but explicitly address interactions between goals primarily through annual reporting on SDG 17 (UN 2016).

In practice, decisions and actions (including research, innovation, policy, and management) are mostly focused on a single SDG, or small subsets of SDGs, because institutions, governance, and research funders are commonly fragmented or siloed (e.g. separate agriculture and climate change departments; natural and social sciences, and medical research funders). Governments may also prioritise those SDGs that can in principle be met at the national scale, especially goals related to human wellbeing (e.g. SDGs 1, 3, 4, 5, 10, 16; Waage et al. 2015).
However, because decisions and actions to advance any one SDG will likely affect the achievement of the others, we need a better understanding of the interactions between SDGs, in particular trade-offs, synergies and unintended consequences.

Another reason for considering interactions between SDGs is the growing evidence that substantial economic, social and environmental benefits can be obtained from wellcoordinated actions that capitalise on synergies between multiple SDGs. For example, targeting energy security (SDG 7), climate change (SDG 13) and air pollution (SDG $3,11,12$ ) simultaneously in energy systems could achieve all three goals for only slightly greater cost than achieving the climate change goal alone (c. $1 \%$ of global GDP vs c. 1.6\%; McCollum et al. 2011). Phasing out solid fuel cooking stoves could reduce global warming by $0.08^{\circ} \mathrm{C}$ by 2050 at the same time as avoiding 260,000 premature deaths per year from local pollution (Lacey et al. 2017) progressing SDGs 13 and 3.

Given that only 10 years remain to achieve all SDGs globally and progress has been insufficient so far (Independent Group of Scientists Appointed by the Secretary-General 2019), there is a growing need to increase the effectiveness and efficiency of action by targeting multiple SDGs. 2020 is a pivotal year for directing action on the environment: new biodiversity targets will be negotiated as part of the UN Convention on Biological Diversity's (CBD) post-2020 agenda, and governments are updating their commitments on climate change (Nationally Determined Contributions) as the Paris Agreement enters into force. There is, therefore, a pressing opportunity to enhance management of the environment to better contribute towards achieving the SDGs, including by understanding and acting on potential synergies and tradeoffs between SDGs.

Assessing interactions between SDGs, and the influence of environment on them can make an important contribution to informing decisions in 2020 and beyond. Here, we review previous assessments of interactions among SDGs, apply a specific method to assess pairwise interactions between all SDGs, and show how viewing these from the perspectives of environment-human linkages can influence the outcome. Lastly, we discuss cross-cutting issues and the relevance and potential application of our approach.

\section{Previous assessments of interactions between SDGs}

One conceptual starting point for analysing interactions between SDGs are the concentric layers diagrams of Griggs et al. (2013) and Waage et al. (2015), which aimed to inform the development of the SDGs. These diagrams show that achievement of the SDGs in an inner circle is dependent on 
achieving those in the outer rings. For example, focusing on governance, Waage et al. (2015) proposed that SDGs related to human wellbeing (shown in the inner circle) are dependent on SDGs that provide the enabling infrastructure for development (the middle ring), and SDGs that provide the supporting natural systems (the outer ring). Griggs et al. highlighted that goals need to integrate social, economic and environmental dimensions (Griggs et al. 2014).

More recently, Folke et al. (2016) provided a threedimensional diagram of concentric layers (the "wedding cake") showing that economies and societies should be seen as embedded parts of the biosphere. Rockström and Sukhdev (2016) assert that all SDGs are directly or indirectly connected to sustainable and healthy food, and suggest that goals on eradicating poverty (SDG 1) and zero hunger (SDG 2) require gender equality (SDG 5), decent jobs (SDG 8) and reduced inequality (SDG 10). Likewise, the framework of the global research initiative The World in 2050 (2018, 2020) shows planetary boundaries delineating the achievement of the SDGs, with five interconnected clusters of SDGs (namely social and economic development [SDGs 8, 9, 11], universal values [SDGs 4, 5, 10], earth preconditions [SDGs $13,14,15]$, sustainable resource use [SDG 6, 7, 12], and basic human needs [SDGs 1, 2, 3]) embedded in partnerships (SDG 17) and governance (SDG 16). Fu et al. (2019) conceptualised interactions among three SDG categories: governance, essential needs, and expected objectives. Governance (encompassing effective regulation, equitable rules and systems; i.e. SDGs 9, 11, 12, 13 and 17) will guarantee meeting essential needs for human survival (SDGs 2, 6, 7, 14 and 15) while maximising expected objectives (SDGs $1,3,4,5,8,10$ and 16). To address the essential needs will require natural science and technology, while social science and ethics are required to maximise the objectives. Other assessments have highlighted much more complex interactions and visualised these using variations on network diagrams. Le Blanc (2015a, b) used textual analysis of the 107 substantive targets of the SDGs (excluding implementation targets) to identify connections between them. This highlights substantial complexity in interactions between SDGs. Some goals have many more connections than others: for instance, SDG 12 has connections to 14 other goals, while SDG 14 is shown connected to only 2 other goals. Being purely based on textual analysis, this network diagram does not capture some of the less explicit aspects of the targets and, therefore, omits interactions shown by more 'interpretive' approaches. For example, ICSU (2015) using a consultative approach to assess interactions, found more links and more complexity in interactions among the SDGs than the textual analysis based on targets.

Several assessments have focused on one SDG or subsets of SDGs. Examples include interlinkages between human health and environment showing SDG 3 as the only goal in the inner circle, with the remaining 16 goals in an outer layer, directly interacting with SDG 3 and not with each other (Fig. 1 in UNEP 2016); assessments of various nexus approaches including the water-energy-food nexus, and the interactions among these subsets (Ritz 2015; Weitz et al. 2015; Liu et al. 2018; McCollum et al. 2018); or the land resource-food price nexus using a dynamic partial equilibrium model of agriculture and forest sectors (Obersteiner et al. 2016). More systematic approaches involving a sevenpoint scale to differentiate between positive $(+3$ to +1$)$, neutral $(0)$ and negative interactions ( -1 to -3 ) between SDGs (Nilsson et al. 2016) have been applied to four goals (SDGs $2,3,7,14)$ using experts to assess target-level interactions between them and key interactions with other SDGs (ICSU 2017). Using a different scoring approach, an in-depth analysis of the relationships between the ocean SDG 14, and its targets, and the other 15 SDGs (excluding SDG 17) used experts to consider three hierarchical dimensions: compatibility of relationship (co-benefit, trade-off, or neutral); requirement of one target for the fulfilment of other target (prerequisite vs optional); and whether the relationship is socio-ecological context-independent vs context-dependent (Singh et al. 2018). The majority of interactions were scored to be synergistic between the four goals (ICSU 2017) or positive for the marine SDG (260 positive and 7 negative relationships Singh et al. 2018). Although providing some insights on potential interdependencies among targets and goals, which may be helpful to inform actions towards SDG achievement, these assessments have been relatively basic by starting from one or a few SDGs then counting interactions and discussing synergies and trade-offs.

To our knowledge, the few assessments that have analysed the interactions between all SDGs have mostly focussed on a defined group of actors. One assessment with the aim of providing guidance for businesses to navigate the SDGs (PwC 2016) identified what it terms "the key links to other SDGs" for each goal. This provides a relatively restrictive subset of interactions between SDGs relevant to companies' operations. Country-specific assessments have focussed on 22 Arab countries assessing 'level of urgency', 'systemic impact', and 'policy gaps' (Allen et al. 2019a), Australia (Allen et al. 2019b), or Sweden (Weitz et al. 2018) latter using the seven-point scale (Nilsson et al. 2016) in an influence (or cross-impact) matrix, assessed all pairwise interactions between two targets from each SDG (excluding SDG 17). Two targets were selected as being of most relevance for Sweden, and the resulting $34 \times 34$ impact matrix showed that most interactions $(96 \%)$ were positive or neutral. Such a matrix could provide useful information for national governments to identify targets and SDGs that offer opportunities and challenges (Breuer et al. 2019). The only quantitative analysis of interactions within and between SDGs through time analysed correlations between time-series data for SDG 


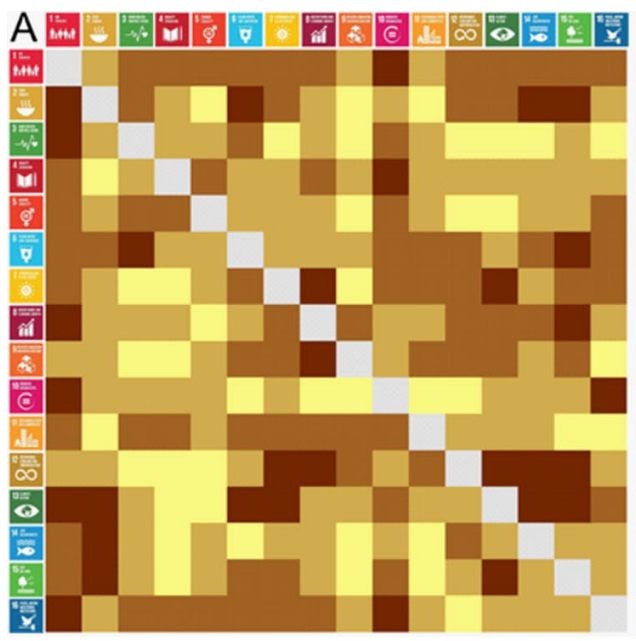

Fig. 1 Influence matrix of 16 SDGs and their interactions assessed by the degree to which action to achieve each SDG (rows) is likely to affect the achievement of other SDGs (columns), considering all possible action (a), and when applying an environment-human perspective (b). Colours in both matrices represent the four-level influence metric, from neglible influence among actions (yellow) to high influence (darkest brown/darkest green); i.e. the darkest row/column intersections in each row are those where the bulk of action directed at achieving an SDG (row label) will have the strongest influence (either positive or negative) on the potential for achieving another goal (column label). For example, much of the action that might be used to achieve SDG 3 (e.g. vaccination and sanitation programmes,

indicators for each country (Pradhan et al. 2017) to identify trade-offs (defined as significant negative Spearman's rank correlations) and synergies (positive correlations). For most countries, positive correlations between indicator pairs within SDGs outweighed negative ones, whereas globally a mix of positive and negative correlations was observed between the SDGs. While the statistical approach highlights correlations, it cannot identify causal or functional interactions as attempted by ICSU (2017).

An assessment of assessments of interactions among goals showed that $92 \%$ of goal level interactions have been assessed and the majority of these were positive interactions or co-benefits (Independent Group of Scientists Appointed by the Secretary-General 2019). The assessment of assessments also highlighted substantial gaps, with only $10 \%$ of target level interactions having been assessed at least once.

Each of the analyses summarised above is useful for the purpose that it was conducted. Because every assessment has used a different approach to examine interactions between SDGs (e.g. different-often unspecified-methods and/or stakeholders, starting with a different single goal, or different subsets of SDGs or targets), few-if any-consistent patterns in the number, or importance, of the interactions between SDGs are emerging globally. For a more in-depth review and critique of frameworks to assess interactions among SDGs, see Breuer et al. (2019). Of all the frameworks

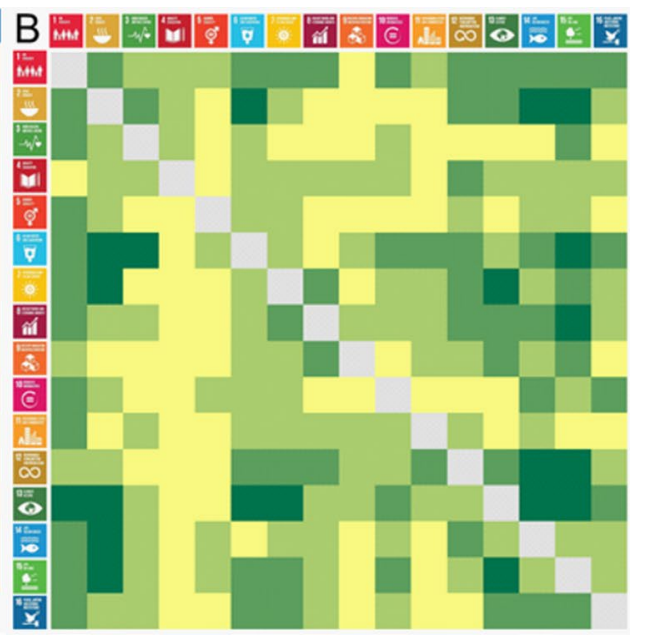

health education, vector control, and research to support these) is likely to affect (either positively or negatively, depending on what it is and how it is implemented) the achievement of all other goals to some degree (row 3, a). However, action to achieve SDG 3 may have particular importance for the potential for achieving SDG 1, and also SDGs 6 and 10. Regardless, only a subset of that action addresses environment-human linkages (shown as paler colour in the equivalent row in b). The darkest cells in each of the columns identify those SDGs (rows) that have the greatest influence on the potential to achieve that goal. For example, the potential to achieve SDG 6 is likely to be especially influenced by environment-human focused action for SDGs 2 and 13

of SDG interactions reviewed, Breuer et al. (2019) concluded that the influence matrix, as implemented by Weitz et al. (2018) for Sweden, can be "a useful starting point for national governments to rationalize targets and identify those that present particular challenges and opportunities in their specific national contexts".

The influence matrix is a promising approach that treats the 2030 Agenda as a whole, i.e. assesses the SDGs role within a system, but so far has only been applied to a single country case study and for a subset of SDG targets (Weitz et al. 2018). This method assesses cause-and-effect relationships within complex, nonlinear systems by using an orthogonal matrix of interactions among items (or variables, factors, events) of a system. It was originally developed by Gordon and Hayward (1968). Below we adapt this method and apply it to assess interactions among all SDGs at global level.

\section{Using an influence matrix to analyse interactions between SDGs}

\section{Influence matrix method}

An influence matrix helps focus attention and resources on the critical factors that have the greatest influence on a 
system. The matrix provides a tool to frame the system under investigation and, using a qualitative metric, makes it possible to combine factors that are not necessarily equivalent or quantifiable (e.g. biophysical and socio-economic factors). Alternatively, quantitative scores could be applied (e.g. scores proposed by Nilsson et al. 2016). An influence matrix will only ever include those factors in the system that are perceived as relevant by experts conducting the assessment.

Using an influence matrix allowed us to consider the role of all SDGs, their targets, and their interactions within the system. We included all SDGs in our assessment except SDG 17, which is an enabling goal that outlines the means of supporting and facilitating the implementation of the other goals. We assessed 240 pairwise interactions between the 16 SDGs $(16 \times 16$ SDGs excluding cells on the main diagonal; Fig. 1). Building on a synthesis of research evidence, key innovations and policies related to each SDG (Scharlemann et al. 2016), a core group of authors determined a qualitative influence score for each pairwise interaction, considering the substantive targets for each SDG (i.e., excluding the implementation targets denoted in the 2030 Agenda by lower case letters). The scoring was reviewed by other authors and an expert advisory board (see Acknowledgements).

At each row/column intersection, we assessed the question: To what degree is an action (e.g. research, innovation, policy, management) to achieve goal $\times($ row) likely to influence the achievement of goal y (column)? This actionfocused assessment is distinct from asking how the achievement of one SDG influences the achievement of another and, therefore, highlights different interactions. We scored each row/column interaction on a four-level influence metric that considered the absolute strength of the interaction, irrespective of whether the influence is positive or negative. The influence metric ranges from negligible influence, where action towards SDG $\times$ (row) is likely to cause no or hardly any change in the potential for achieving SDG y (column), to high influence, where a wide range of action directed towards addressing SDG $\times$ will likely influence strongly the potential for achieving SDG y. An advantage of assessing absolute interaction strength is that negative and positive aspects do not get averaged out.

\section{Findings of SDG interaction assessment using an influence matrix}

Overall, the majority (83\%) of interactions showed some level of influence among SDG pairs, with 13\% (32 row/column intersections) identified as high influence interactions and 17\% (41 intersections) assessed as negligible (Fig. 1a).

In each row of Fig. 1a, the darkest row/column intersections are those where the bulk of action directed at achieving an SDG (row) will have the strongest influence on the potential for achieving another SDG (column). For example, much of the action that might be used to achieve health-related SDG 3 (e.g. vaccination and sanitation programmes, health education, vector control, and research to support these) is likely to affect (either positively or negatively, depending on the action and how it is implemented) the achievement of all other SDGs to some degree (row 3, Fig. 1a). In particular, action to achieve SDG 3 may have a high influence on the potential for achieving SDG 1, and also SDGs 6 and 10 . Reading down each column, the darkest intersections identify those SDGs (rows) that have the greatest influence on the potential to achieve that column goal. For example, the potential to achieve water-related SDG 6 (column) is likely to be especially influenced by action towards SDGs 2 and 13 .

Note that pairwise interactions are not all equally strong when viewed in row or column directions. For example, not all of the wide range of action taken to ensure clean water and sanitation (SDG 6, row) will influence progress on combatting climate change (SDG 13, column), whereas most action directed towards combatting climate change (SDG 13, row) will influence the availability of clean water (SDG 6, column).

\section{The influence of perspective on assessments of SDG interactions}

Although the SDGs form an indivisible whole and progress towards them will require a holistic approach, in practice decisions and action tend to address more specific challenges and opportunities, often focused on sectors and/or at national or smaller spatial scales. Therefore, it is crucial to understand how deliberately taking different perspectives may influence the multiple dimensions of progress towards sustainable development, as well as the interdependencies, co-benefits and trade-offs among SDGs.

Using a specific perspective to analyse interactions among all SDGs (and their targets) will likely provide a more holistic assessment of the interactions than previous sectoral approaches which have focussed on subsets of SDGs (or targets) (e.g. PwC 2016; ICSU 2017; Weitz et al. 2018). This can be done by completing an influence matrix of all SDGs from a specific perspective, effectively ensuring that the assessment treats the SDGs as an indivisible whole, while also recognising that interactions between actions towards achieving SDGs may differ depending on the context. SDG interactions may differ according to perspectives linked to factors such as geographic, political or temporal scale (e.g. local, national; Weitz et al. 2018), sectoral focus (e.g. business PwC 2016, finance, agriculture, environment), or social group (e.g. women, youth, indigenous people). For example, actions taken at one spatial scale (e.g. regional) to support the achievement of one SDG, may have impacts at other scales (e.g. local or global). Similarly, immediate outcomes of actions potentially differ from longer-term impacts 
both in their relevance to particular SDGs, and in whether their effects are predominantly positive or negative. Moreover, synergistic interactions between SDGs today may turn into trade-offs in the longer term, or vice versa. For example, drilling boreholes may provide drinking water in the short term (addressing SDG 6), but, in the longer-term, may lower the water table and reduce access to drinking water (SDG 6), and negatively affect food production (SDG 2) and natural vegetation (SDG 15). Furthermore, action may have benefits at one spatial or temporal scale, but adverse impacts at another, e.g. through teleconnections.

\section{Interactions between SDGs from an environment- human linkage perspective}

Linkages between the environment and humans ${ }^{1}$ play a central role in sustainable development (MA 2005; Díaz et al. 2015), and the environment has been recognised as fundamental for the achievement of many or all of the SDGs (e.g. UNEP 2015; Waage et al. 2015; Folke et al. 2016). A textual analysis confirms that the environment is integral to most SDGs (13 SDGs contain at least one environment-related word, aspects of the environment are mentioned in 62 of 150 targets [excluding SDG 17 and its 19 targets], and three SDGs with 27 targets are focused entirely on the environment [SDGs 13, 14, 15]; Fig. 2). For some SDGs, action addressing environment-human linkages (i.e. ways in which environment and humans affect one another) are central to achieving all their targets (SDGs 13, 14 and 15), whereas for others, environment-human linkages most likely form a smaller part of the overall action required to achieve the goal (e.g. SDGs 4 and 10).

On one hand, environment-humans linkages include both nature's contributions or services to people (e.g. provisioning of oil, regulating of climate, etc.) and the negative disservices it provides (e.g. floods, disease, etc.) (Díaz et al. 2015, 2018). On the other hand, these linkages also include the impacts humans have on the environment, both positive (e.g. protecting and restoring ecosystems, conserving species, etc.) and negative (e.g. pollution of water, degradation of soils, etc.).

\footnotetext{
1 We define 'environment' broadly to encompass the "totality of all the external conditions affecting the life, development and survival of" humans (OECD 2016) and include planetary systems (e.g. climate and hydrological systems), geological resources (e.g. mineral and energy resources) and ecosystem capital (land, soil, biological resources, water resources, ecosystem functions) (UN Statistics Division London Group on Environmental Accounting 2014). While 'humans' encompasses people and the knowledge, skills, competencies and attributes embodied in individuals (human capital), and the "networks together with shared norms, values and understandings that facilitate co-operation within or among groups" (social capital) (Keeley, 2007).
}
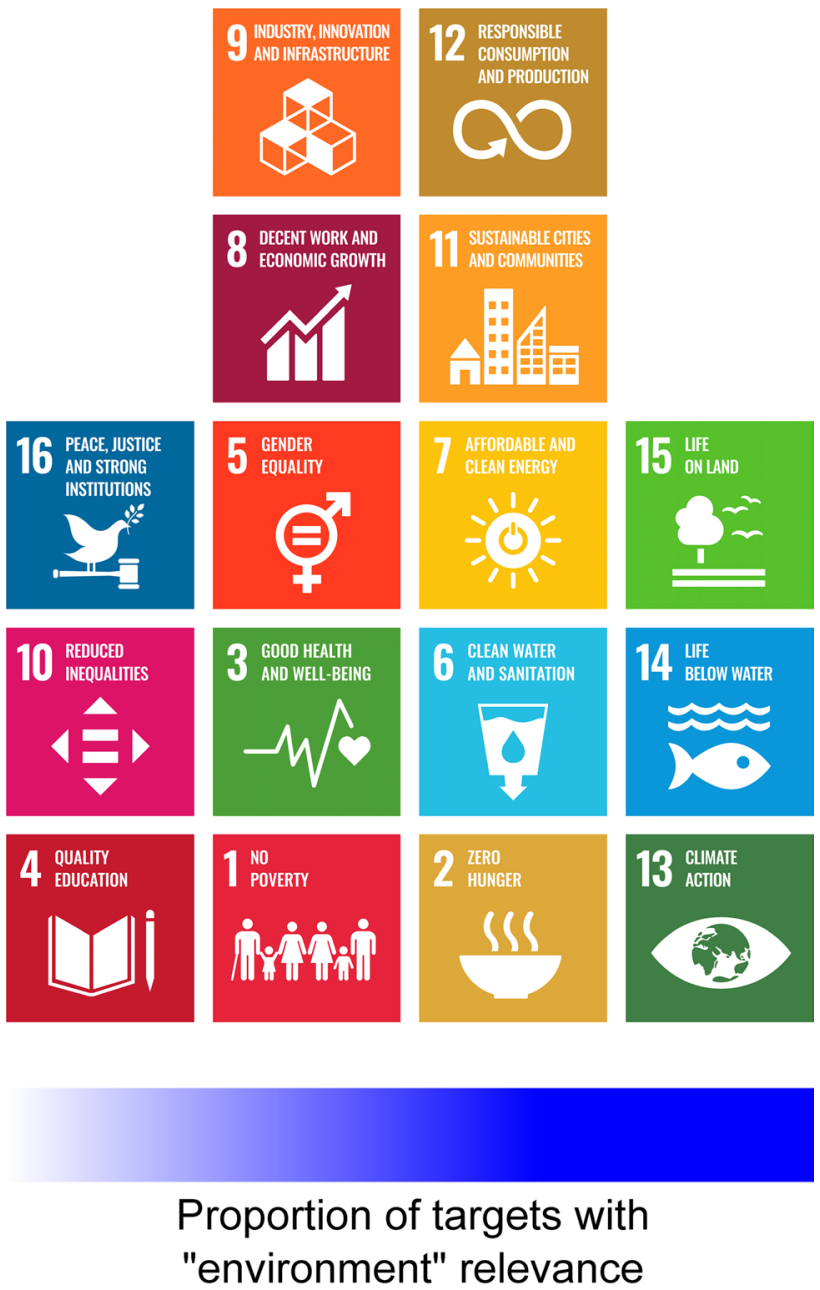

Fig. 2 The importance of environment within each SDG, based on a textual analysis of SDG target wording (as per UN 2015). The vertical scale is linked to the proportion of targets within each SDG that contain at least one environment-related word (Environment-related words were counted within each SDG target, and include: air, animal, aquaculture, aquifer, biodiversity, clean energy, climate, coastal, communicable disease, drought, dryland, ecosystem, environment, fauna, fish, flood, flora, forest, genetic diversity/resources, green space, hepatitis, lake, land, livestock, local product, malaria, marine, mountain, natural, nature, neglected tropical disease, ocean, pastoralist, periurban area, plant, renewable energy, resource, river, rural area, sea, seed, services, soil, species, terrestrial ecosystem, tuberculosis, water, weather, wetland, wildlife. The count included close relatives of each word, e.g. *fish* also selected fishing, fisheries, overfishing, etc..), and ranges from no mention of the environment (SDGs 4, 10, 16) to environment mentioned throughout (SDGs 13, 14, 15)

To assess the environment-human aspects of the interactions between SDGs, we applied the logic explained above but focused only on action related to the environment-human linkages rather than the full range of possible actions to advance any one SDG. For example, some action used to achieve good health and wellbeing (SDG 3) is related to the environment-human linkages, e.g. vector 
control, while other action, e.g. vaccination programmes, is not. In the resulting influence matrix (Fig. 1b) the darkest row/column intersections show where environment-human linkages may be most influential; there are 20 such pairwise interactions.

Comparing this influence matrix with the previous onegenerated without a specific perspective- -highlights differences resulting from the focus on action related to environment-human linkages (Fig. 1a, b). For example, from the perspective of environment-human linkages, action to achieve affordable and clean energy (SDG 7) may have a stronger influence on the potential to achieve less hunger (SDG 2; Fig. 1b) than when all action is considered (Fig. 1a). This is because only a subset of action towards affordable and clean energy, such as production of biofuel feedstocks, involves environment-human linkages and most of these will influence the potential for achieving food security. In contrast, the broader assessment (Fig. 1a) includes many technological solutions, such as solar and geothermal energy production, that may have little influence on food security (though, in principle, any form of energy efficiency may enhance food production), resulting in a lower influence score. Addressing environment-human linkages is only part of the action required to make progress on health and well-being (SDG 3), and may have less influence on the achievement of gender equality (SDG 5) than the full range of health-related action. In many cases the influence scores are similar in both matrices; for example, nearly all actions towards achieving food security (SDG 2) influence the potential to achieve clean water and sanitation (SDG 6).

The differences in influence scores for individual row/ column intersections generate wider differences in pattern between the two matrices. For example, the potential for achieving SDGs 3, 4, 5 is in general less influenced by actions related to environment-human linkages than by the full suite of actions towards other SDGs (pale columns for SDGs 3, 4, 5 in Fig. 1b). Because the bulk of action directed towards achieving the environment-focussed SDGs $(13,14$, 15; Fig. 2) is environment-human linkage focussed, there is a high degree of similarity in influence scores between the two matrices (rows for SDGs 13, 14, 15 in Fig. 1a, b).

\section{Discussion}

This assessment emphasises the importance of the environment, and environment-human linkages, in influencing interactions between all SDGs. Focussing on these factors highlights that the way we manage the environment matters for achieving the SDGs and the potential to build on synergies and reduce trade-offs between particular SDGs.
Our assessment also shows that this potential varies among SDG interactions.

The assessment focussed on actions, rather than on SDG achievement, introduced above enables decision makers to see where the choices on environmental management may have the greatest impacts, and may also enable sectoral decision makers to seek support from environment managers for achieving their goals.

The holistic overview of an influence matrix provides across all 17 SDGs helps to anticipate indirect impacts, unintended consequences, and potentially teleconnections. This can inform integrated and more effective planning and decision making at national (e.g. Sweden, Weitz et al. 2018) and other scales. Insights relevant to sectoral and stakeholder concerns can be gained by applying additional perspectives to such an assessment, for example by focussing on specific geographic, political or temporal scales, or on specific sectors or social groups.

Several cross-cutting factors can shape both the interactions between SDGs and the ways in which actions lead to the achievement of goals. These factors need to be considered regardless of perspective, e.g. whether the focus is on environment-human related actions, or on all actions to achieve the SDGs. These factors include available knowledge; thresholds and tipping points; stakeholder involvement in assessment and implementation; (multi-)directionality of interactions between SDGs; number and types of people affected; context including governance, institutions and power. These cross-cutting factors are part of the 'means of implementation' in SDG 17 and in the 42 implementation targets (denoted by letters) within each SDG, and interactions among these should also be considered (Stafford-Smith et al. 2017)

Our assessment of the interactions between SDGs and the potential actions to achieve them are influenced by the state and accessibility of knowledge on relevant issues and processes. We based our assessment largely on scientific knowledge (from natural and social sciences, and interdisciplinary approaches) while recognising the importance of indigenous and local knowledge as well as private sector knowledge and innovation, although these are often less accessible. The amount, availability, relevance and relative importance of each of these types of knowledge differ among SDGs, and between different locations, contexts and groups of actors. Each knowledge type may provide different viewpoints on appropriate courses of action and their likely outcomes for different SDGs. Approaches that integrate knowledge from these multiple sources may provide further insights.

Furthermore, available knowledge is (and will likely remain) incomplete. The process of completing an influence matrix can help identify knowledge gaps, where more research is needed, as well as identify interactions with negligible influence where further research may be less 
important. Such matrices have been used to identify interactions most sensitive to a better understanding within integrated assessment models (van Vuuren et al. 2018; van Soest et al. 2019). Knowledge gaps in the environment-human linkages have been identified by Carpenter et al. (2009) and in Scharlemann et al. (2016). Substantial time will be required to develop, resource and implement programmes of research to address knowledge gaps, and yet more to integrate the results into decision-making and act on them at a sufficient scale to make a measurable difference to established trajectories. An "SDG Interactions Knowledge Platform" as proposed by Future Earth (Nilsson et al. 2018) may help "assembling, systematizing and aggregating knowledge on interactions", including evidence on what policy and actions work in particular contexts.

One key knowledge gap concerns thresholds and tipping points. Change in social-ecological systems may be linear and gradual under some circumstances, but there is increasing evidence that unsustainable use and other factors may mean that thresholds are crossed, or tipping points reached, prompting abrupt change and transition to novel states (Scheffer 2009). Depending on the context, action to achieve one SDG may generate a tipping point or system transition that could dramatically affect the ability to achieve another goal. Improved knowledge of thresholds and tipping points would inform understanding of interactions between SDGs and would be crucial to SDG achievement, for example, the hypothesised Amazon forest dieback with concomitant socio-economic impacts (Lapola et al. 2018).

Our assessments represent a view of SDG interactions based on the knowledge and potential inherent biases of the participants involved in the qualitative scoring of the influence matrices. Future assessments would benefit from more careful identification of the stakeholders and inputs needed (Cole et al. 2007). Furthermore, drawing on quantitative information provided by the SDG indicators (either at global or sub-global levels) (United Nations Department of Economic And Social Affairs 2020) could help inform the qualitative expert process to establish a 'score' for the relationship between any two SDGs.

The influence metric used considers the absolute strengths of potential influences, rather than their direction, i.e. strongly positive and strongly negative influences are both considered strong influences (and do not cancel each other). Differences among options for action, as well as variation across scales and contexts, mean that interactions between SDGs may encompass both complementarity and conflict. An alternative metric could be applied that considers both positive and negative interactions and quantifies strengths (e.g. scores proposed by Nilsson et al. 2016), although positive and negative aspects cancel each other out in this metric. Applying these complementary approaches to explore SDG interactions could provide a more holistic understanding. Furthermore, none of the available influence metrics currently capture uncertainty in the strength or in the direction of interactions.

The scale of implementation determines the number and types of people affected and consequently the potential outcomes for other SDGs. For example, some action towards an SDG may result in trade-offs at a local scale while contributing to progress at larger scales.

Like a scale, other aspects of the context for SDG-related action also affect interactions between SDGs and the ways in which actions lead to goal achievement. Governance, the process through which individuals and institutions, public and private, depend on and interact with each other for decision-making across sectors and institutional scales, plays a crucial role in SDG interactions and SDG achievement. For a holistic assessment, we included interactions at goal level for 16 SDGs, resulting in 240 goal by goal interactions, while also considering targets within goals when scoring the influence metric. For a more in-depth assessment target by target interactions could be assessed, resulting in 28,392 (or 11,342 ) interactions when all 169 (or 107 substantive) targets are being included. Such assessment would require substantial resources, although machine learning or text analysis tools could help screen for most relevant interactions.

Interactions will not only occur between two SDGs, but can also be three-, four-, and theoretically up to 17-way. For example, action on energy (SDG 7) directly impacts food production (SDG 2) through direct competition for land, and also through emissions affecting climate change (SDG 13), and strategies for combatting climate change in turn impact food production (SDG 2). However, focussing on two-way interactions provides a tractable way to begin to understand this complexity.

\section{Potential ways forward in addressing the interlinked challenges of the SDGs}

Despite these limitations, the influence matrix provides valuable insight on the interlinked challenges of taking action towards SDG achievement, and how they vary with perspective. To focus on quantitative outcomes and/or identify opportunities for decision making, other approaches may be more appropriate. Several emerging approaches, practices, and research communities can then help tackle the identified challenges, either in concert or singly, and support decision making. We present several such approaches below ranging from more qualitative to more quantitative.

The 'pathways approach' aims to guide thinking and action around sustainability challenges by framing any given issue in terms of complex, dynamic and interacting socio-ecological systems that can change along various potential pathways (Leach et al. 2007). Pathway framings by stakeholders will lead to different narratives about the 
same system and ultimately different decisions and actions. Recognising that framings and pathways of powerful actors and institutions can become the dominant approach for channelling action, the 'pathways approach' aims to include non-obvious pathways or those currently blocked by local circumstance (Leach et al. 2007). By considering multiple framings, pathways towards more plural and dynamic sustainable systems are likely to emerge.

Transition management aims to facilitate and accelerate transitions towards sustainability by bringing together multiple viewpoints and approaches. Shared visions are developed to address problems with current systems, and strategies implemented as an experiment to encourage adaptive learning and policymaking (Loorbach 2010). Such an approach is being trialled in the Netherlands to address sustainable development (Loorbach 2010). An influence matrix could be used in policy planning, or to scan for policy options in a transdisciplinary scenario analysis to help identify how certain policies may affect the achievement of SDGs.

Integrated systems-thinking can help navigate socialecological complexity and transcend disciplinary boundaries. Leverage points are system properties where a small shift can lead to fundamental changes in the system as a whole (Meadows 1999). These points can be used to target interventions that address ultimate causes of or barriers to sustainability, rather than just tackling feedbacks (interactions between elements of systems) or parameters (characteristics or physical elements of systems) (Abson et al. 2017). Three interacting realms of leverage have been proposed for sustainability transformation: (1) the role of institutions; (2) people's connections to nature and their influences on sustainability outcomes; and (3) knowledge production and use in transformational processes (Abson et al. 2017).

To cope and adapt to change, people often rely on traditional and local knowledge, cultural values and customary institutions, which can contribute to integrated solutions needed to effect transformational change (UNSAB 2016). For example, indigenous peoples' context-specific knowledge supports communities to develop and successfully implement sustainable land management (Mistry and Berardi 2016) and enhances ecosystem management for human wellbeing (Tengö et al. 2014). Recognition, protection and promotion of indigenous and local knowledge can strengthen economic, environmental, social and cultural resilience within societies, and form the knowledge base for addressing critical sustainability problems (UNSAB 2016).

Integrated environmental assessments critically evaluate knowledge on a particular topic and identify response options by bringing together experts from different disciplines (Ash et al. 2010; UNEP 2010). The process itself is also of value, as it provides an opportunity for increased engagement among experts, decision-makers and other stakeholders long before the final assessment products are produced (Ash et al. 2010). Examples include the UNEP's Global Environment Outlook (UNEP 2010), Millennium Ecosystem Assessment (MA 2005), assessment reports by the Intergovernmental Panel on Climate Change (IPCC 2014), and Intergovernmental Platform on Biodiversity and Ecosystem Services (IPBES 2019).

Integrated assessment models, qualitative or quantitative descriptions of key components of a system and the functional relationships between them, can help guide understanding of complex and long-term issues, and of impacts of policy options. Together with scenarios (representations of possible futures for one or more components of a system), these models are often embedded in assessments (see above) to help inform policy and decision-making (IPBES 2016). Examples include climate change and pollution models, and more recently, multiple integrated models (overview in IPBES 2016) as well as a model that addresses SDG interactions (Millennium Institute 2017). Developing integrated models to assess all SDGs and their interactions will likely require linking and harmonising models across multiple domains, which is challenging (Cheung et al. 2016) as not all SDGs are well represented within integrated assessment models (van Vuuren et al. 2018; van Soest et al. 2019).

\section{Conclusions}

We have demonstrated that environment-human linkages affect outcomes of the vast majority of SDG interactions. This means that the environment needs to be considered in national and other efforts to achieve all SDGs, and these considerations should inform the CBD's post-2020 agenda and national commitments under the Paris agreement.

The influence matrix method could be applied to guide both implementations of existing policies, such as national legislation and commitments, and development and subsequent implementation of new policies, such as the CBD's post-2020 global biodiversity framework (CBD 2020). As the development of the multiple targets of the framework progresses, the influence matrix method could be used to assess interactions among targets and internal coherence of the developing framework. It could also help evaluate and adjust the framework to meet the declared need for it to complement and support SDG implementation. Taking an action-focused approach to this kind of assessment increases its utility for supporting decision making. In practice, decisions are being made at national, subnational or corporate scales (focussing largely on current issues) by individuals with existing sectoral perspectives. To help them consider the potential influences of their decisions on other sectors and objectives, approaches that make additional perspectives explicit are needed. Applying perspective to an influence matrix is one helpful approach. However, an influence 
matrix is only one of several essential steps to prioritise action towards the achievement of policy goals. Prioritisation of action requires an iterative, participatory process that considers cross-cutting factors.

Given the timeframes for SDG achievement and the international environmental policy developments in 2020, developing and acting on a more in-depth understanding of the role of the environment in synergies and trade-offs between SDGs is urgent. Doing so could also help identify where and which environmental safeguards need to be put in place to reduce the risk that efforts to achieve all SDGs may have intended or unintended adverse environmental consequences.

Acknowledgements We would like to thank members of the Global Goals Mapping: The Environment-human Landscape project expert advisory group for their guidance: J. Alcamo, N. Ash, M. Leach, and G. Mace; and C. Grundy for project administration. This research was supported by the UK Natural Environment Research Council (NERC Grant number: GGM10001 \& PS16129) as part of the Towards a Sustainable Earth initiative commissioned by NERC, the Economic and Social Research Council (ESRC) and the Rockefeller Foundation. This is a contribution from the Sussex Sustainability Research Programme.

Open Access This article is licensed under a Creative Commons Attribution 4.0 International License, which permits use, sharing, adaptation, distribution and reproduction in any medium or format, as long as you give appropriate credit to the original author(s) and the source, provide a link to the Creative Commons licence, and indicate if changes were made. The images or other third party material in this article are included in the article's Creative Commons licence, unless indicated otherwise in a credit line to the material. If material is not included in the article's Creative Commons licence and your intended use is not permitted by statutory regulation or exceeds the permitted use, you will need to obtain permission directly from the copyright holder. To view a copy of this licence, visit http://creativecommons.org/licenses/by/4.0/.

\section{References}

Abson DJ, Fischer J, Leventon J, Newig J, Schomerus T, Vilsmaier $\mathrm{U}$, von Wehrden H, Abernethy P, Ives CD, Jager NW, Lang DJ (2017) Leverage points for sustainability transformation. Ambio 46:30-39. https://doi.org/10.1007/s13280-016-0800-y

Allen C, Metternicht G, Wiedmann T (2019a) Prioritising SDG targets: assessing baselines, gaps and interlinkages. Sustain Sci 14:421438. https://doi.org/10.1007/s11625-018-0596-8

Allen C, Metternicht G, Wiedmann T, Pedercini M (2019b) Greater gains for Australia by tackling all SDGs but the last steps will be the most challenging. Nat Sustain 2:1041-1050. https://doi. org/10.1038/s41893-019-0409-9

Ash N, Blanco H, Brown C, Garcia K, Henrichs T, Lucas N, RaudseppHearne C, Simpson RD, Scholes R, Tomich TP, Vira B, Zurek M (2010) Ecosystems and human well-being: a manual for assessment practitioners. Island Press, Washington, DC

Breuer A, Janetschek H, Malerba D (2019) Translating Sustainable Development Goal (SDG) interdependencies into policy advice. Sustainability 11:20. https://doi.org/10.3390/su11072092

Carpenter SR, Mooney HA, Agard J, Capistrano D, DeFries RS, Díaz S, Dietz T, Duraiappah AK, Oteng-Yeboah A, Pereira HM,
Perrings C, Reid WV, Sarukhan J, Scholes RJ, Whyte A (2009) Science for managing ecosystem services: beyond the Millennium Ecosystem Assessment. Proc Natl Acad Sci 106:1305-1312. https ://doi.org/10.1073/pnas.0808772106

CBD (2010) The strategic plan for biodiversity 2011-2020 and the Aichi biodiversity targets. UNEP/CBD/COP/DEC/X/2. Convention on Biological Diversity, Montreal, $\mathrm{p} 13$

CBD (2020) Zero draft of the post-2020 global biodiversity framework. CBD/WG2020/2/3. Convention on Biological Diversity, Montreal, p 14

Cheung WWL, Rondinini C, Avtar R, Mvd B, Hickler T, Metzger JP, Scharlemann JPW, Velez-Liendo X, Yue TX (2016) Linking and harmonizing scenarios and models across scales and domains. In: Ferrier S, Ninan KN, Leadley P, Alkemade R, Acosta LA, Akçakaya HR, Brotons L, Cheung WWL, Christensen V, Harhash KA, KabuboMariara J, Lundquist C, Obersteiner M, Pereira H, Peterson G, Pichs-Madruga R, Ravindranath N, Rondinini C, Wintle BA (eds) Methodological assessment of scenarios and models of biodiversity and ecosystem services. Secretariat of the Intergovernmental Platform for Biodiversity and Ecosystem Services, Bonn, pp 244-278

Cole A, Allen W, Kilvington M, Fenemor A, Bowden B (2007) Participatory modelling with an influence matrix and the calculation of whole-of-system sustainability values. Int J Sustain Dev 10:382-401. https://doi.org/10.1504/ijsd.2007.017911

Díaz S, Demissew S, Carabias J, Joly C, Lonsdale M, Ash N, Larigauderie A, Adhikari JR, Arico S, Báldi A, Bartuska A, Baste IA, Bilgin A, Brondizio E, Chan KMA, Figueroa VE, Duraiappah A, Fischer M, Hill R, Koetz T, Leadley P, Lyver P, Mace GM, Martin-Lopez B, Okumura M, Pacheco D, Pascual U, Pérez ES, Reyers B, Roth E, Saito O, Scholes RJ, Sharma N, Tallis H, Thaman R, Watson R, Yahara T, Hamid ZA, Akosim C, Al-Hafedh Y, Allahverdiyev R, Amankwah E, Asah ST, Asfaw Z, Bartus G, Brooks LA, Caillaux J, Dalle G, Darnaedi D, Driver A, Erpul G, Escobar-Eyzaguirre P, Failler P, Fouda AMM, Fu B, Gundimeda H, Hashimoto S, Homer F, Lavorel S, Lichtenstein G, Mala WA, Mandivenyi W, Matczak P, Mbizvo C, Mehrdadi M, Metzger JP, Mikissa JB, Moller H, Mooney HA, Mumby P, Nagendra H, Nesshover C, Oteng-Yeboah AA, Pataki G, Roué M, Rubis J, Schultz M, Smith P, Sumaila R, Takeuchi K, Thomas S, Verma M, YeoChang Y, Zlatanova D (2015) The IPBES conceptual framework - connecting nature and people. Curr Opin Environ Sustain 14:1-16. https://doi.org/10.1016/j.cosust.2014.11.002

Díaz S, Pascual U, Stenseke M, Martín-López B, Watson RT, Molnár Z, Hill R, Chan KMA, Baste IA, Brauman KA, Polasky S, Church A, Lonsdale M, Larigauderie A, Leadley PW, van Oudenhoven APE, van der Plaat F, Schröter M, Lavorel S, Aumeeruddy-Thomas Y, Bukvareva E, Davies K, Demissew S, Erpul G, Failler P, Guerra CA, Hewitt CL, Keune H, Lindley S, Shirayama Y (2018) Assessing nature's contributions to people. Science 359:270-272. https ://doi.org/10.1126/science.aap8826

Folke C, Biggs R, Norström AV, Reyers B, Rockström J (2016) Socialecological resilience and biosphere-based sustainability science. Ecol Soc 21:41. https://doi.org/10.5751/ES-08748-210341

Fu B, Wang S, Zhang J, Hou Z, Li J (2019) Unravelling the complexity in achieving the 17 sustainable-development goals. Natl Sci Rev 6:386-388. https://doi.org/10.1093/nsr/nwz038

Gordon TJ, Hayward H (1968) Initial experiments with the cross impact matrix method of forecasting. Futures 1:100-116. https:// doi.org/10.1016/S0016-3287(68)80003-5

Griggs D, Smith MS, Rockström J, Ohman MC, Gaffney O, Glaser G, Kanie N, Noble I, Steffen W, Shyamsundar P (2014) An integrated framework for sustainable development goals. Ecol Soc 19:24. https://doi.org/10.5751/es-07082-190449

Griggs D, Stafford-Smith M, Gaffney O, Rockström J, Ohman MC, Shyamsundar P, Steffen W, Glaser G, Kanie N, Noble I (2013) 
Sustainable development goals for people and planet. Nature 495:305-307

ICSU (2015) Review of the sustainable development goals: the science perspective. International Council for Science (ICSU), Paris

ICSU (2017) A guide to SDG interactions: from science to implementation. In: Griggs DJ, Nilsson M, Stevance A, McCollum D (eds) International Council for Science (ICSU), Paris, p 236

Independent Group of Scientists appointed by the Secretary-General (2019) Global Sustainable Development Report 2019: The future is now-science for achieving sustainable development. United Nations, New York

IPBES (2016) The methodological assessment report on scenarios and models of biodiversity and ecosystem services. In: Ferrier $\mathrm{S}$, Ninan KN, Leadley P, Alkemade R, Acosta LA, Akçakaya HR, Brotons L, Cheung WWL, Christensen V, Harhash KA, KabuboMariara J, Lundquist C, Obersteiner M, Pereira HM, Peterson G, Pichs-Madruga R, Ravindranath N, Rondinini C, Wintle BA (eds) Secretariat of the Intergovernmental Science-Policy Platform on Biodiversity and Ecosystem Services, Bonn, p 348

IPBES (2019) Summary for policymakers of the global assessment report on biodiversity and ecosystem services of the Intergovernmental Science-Policy Platform on Biodiversity and Ecosystem Services. In: Díaz S, Settele J, Brondizio ES, Ngo HT, Guèze M, Agard J, Arneth A, Balvanera P, Brauman KA, Butchart SHM, Chan KMA, Garibaldi LA, Ichii K, Liu J, Subramanian SM, Midgley GF, Miloslavich P, Molnár Z, Obura D, Pfaff A, Polasky S, Purvis A, Razzaque J, Reyers B, Chowdhury RR, Shin YJ, Visseren-Hamakers IJ, Willis KJ, Zayas CN (eds) IPBES secretariat, Bonn, p 44

IPCC (2014) Climate Change 2014: synthesis report. In: Pachauri RK, Meyer LA (eds) Contribution of working groups I, II and III to the fifth assessment report of the intergovernmental panel on climate change. IPCC, Geneva, p 151

Keeley B (2007) Human capital: how what you know shapes your life. Organisation for Economic Cooperation and Development, Paris

Lacey FG, Henze DK, Lee CJ, van Donkelaar A, Martin RV (2017) Transient climate and ambient health impacts due to national solid fuel cookstove emissions. Proc Natl Acad Sci 114:1269. https:// doi.org/10.1073/pnas.1612430114

Lapola DM, Pinho P, Quesada CA, Strassburg BBN, Rammig A, Kruijt B, Brown F, Ometto JPHB, Premebida A, Marengo JA, Vergara W, Nobre CA (2018) Limiting the high impacts of Amazon forest dieback with no-regrets science and policy action. Proc Natl Acad Sci 115:11671-11679. https://doi.org/10.1073/pnas.1721770115

Le Blanc D (2015a) Towards integration at last? The sustainable development goals as a network of targets. Sustain Dev 23:176-187

Le Blanc D (2015b) Towards integration at last? The sustainable development goals as a network of targets. In: UN Department of Economic and Social Affairs. Working paper no. 141 ST/ESA/2015/ DWP/141

Leach M, Scoones I, Stirling A (2007) Pathways to sustainability: an overview of the STEPS Centre approach. STEPS Centre, Brighton

Liu J, Hull V, Godfray HCJ, Tilman D, Gleick P, Hoff H, Pahl-Wostl C, Xu Z, Chung MG, Sun J, Li S (2018) Nexus approaches to global sustainable development. Nat Sustain 1:466-476. https:// doi.org/10.1038/s41893-018-0135-8

Loorbach D (2010) Transition management for sustainable development: a prescriptive, complexity-based governance framework. Governance 23:161-183. https://doi.org/10.111 1/j.1468-0491.2009.01471.x

MA (2005) Millennium Ecosystem Assessment. Ecosystems and human well-being: synthesis. Island Press, Washington, DC

McCollum DL, Krey V, Riahi K (2011) An integrated approach to energy sustainability. Nat Clim Change 1:428. https://doi. org/10.1038/nclimate1297
McCollum DL, Echeverri LG, Busch S, Pachauri S, Parkinson S, Rogelj J, Krey V, Minx JC, Nilsson M, Stevance A-S, Riahi K (2018) Connecting the sustainable development goals by their energy inter-linkages. Environ Res Lett 13:033006. https://doi. org/10.1088/1748-9326/aaafe3

Meadows DH (1999) Leverage points: places to intervene in a system. Sustainability Institute, Hartland

Millennium Institute (2017) Threshold 21 (T21) iSDG model: model documentation. Millennium Institute, Washington, DC

Mistry J, Berardi A (2016) Bridging indigenous and scientific knowledge. Science 352:1274-1275

Nilsson M, Griggs D, Visbeck M (2016) Map the interactions between sustainable development goals. Nature 534:320-322

Nilsson M, Chisholm E, Griggs D, Howden-Chapman P, McCollum D, Messerli P, Neumann B, Stevance A-S, Visbeck M, StaffordSmith M (2018) Mapping interactions between the sustainable development goals: lessons learned and ways forward. Sustain Sci 13:1489-1503. https://doi.org/10.1007/s11625-018-0604-Z

Obersteiner M, Walsh B, Frank S, Havlík P, Cantele M, Liu J, Palazzo A, Herrero M, Lu Y, Mosnier A, Valin H, Riahi K, Kraxner F, Fritz S, van Vuuren D (2016) Assessing the land resourcefood price nexus of the sustainable development goals. Sci Adv 2:e1501499. https://doi.org/10.1126/sciadv.1501499

OECD (2016) Glossary of statistical terms: environment. https://stats .oecd.org/glossary/detail.asp?ID=813. Accessed 08 Aug 2016

Pradhan P, Costa L, Rybski D, Lucht W, Kropp JP (2017) A systematic study of sustainable development goal (SDG) interactions. Earth's Future 5:1169-1179. https://doi.org/10.1002/2017ef000632

PwC (2016) Navigating the SDGs: a business guide to engaging with the UN global goals. PricewaterhouseCoopers, London

Ritz J (2015) The oceans, seas, marine resources and human well-being nexus. In: Global Sustainable Development Report: 2015 edition. United Nations, pp 53-68

Rockström J, Sukhdev P (2016) How food connects all the SDGs. https ://www.stockholmresilience.org/research/research-news/2016-0614-how-food-connects-all-the-sdgs.html. Accessed 31 Mar 2020

Scharlemann JPW, Mant RC, Balfour N, Brown C, Burgess ND, Guth M, Ingram DJ, Martin R, Wicander S, Kapos V (2016) Global goals mapping: the environment-human landscape. A contribution towards the NERC, Rockefeller foundation and ESRC initiative, towards a sustainable earth: environment-human systems and the UN global goals. World Conservation Monitoring Centre, Brighton

Scheffer M (2009) Critical transitions in nature and society. Princeton University Press, Princeton

Singh GG, Cisneros-Montemayor AM, Swartz W, Cheung W, Guy JA, Kenny T-A, McOwen CJ, Asch R, Geffert JL, Wabnitz CCC, Sumaila R, Hanich Q, Ota Y (2018) A rapid assessment of cobenefits and trade-offs among sustainable development goals. Mar Policy 93:223-231. https://doi.org/10.1016/j.marpol.2017.05.030

Stafford-Smith M, Griggs D, Gaffney O, Ullah F, Reyers B, Kanie N, Stigson B, Shrivastava P, Leach M, O'Connell D (2017) Integration: the key to implementing the sustainable development goals. Sustain Sci 12:911-919. https://doi.org/10.1007/s1162 5-016-0383-3

Tengö M, Brondizio ES, Elmqvist T, Malmer P, Spierenburg M (2014) Connecting diverse knowledge systems for enhanced ecosystem governance: the multiple evidence base approach. Ambio 43:579591. https://doi.org/10.1007/s13280-014-0501-3

Tosun J, Leininger J (2017) Governing the interlinkages between the sustainable development goals: approaches to attain policy integration. Glob Chall 1:1700036. https://doi.org/10.1002/ gch2.201700036

The World in 2050 (TWI2050) (2018) Transformations to achieve the Sustainable Development Goals. In: Report prepared by the World 
in 2050 initiative. International Institute for Applied Systems Analysis (IIASA), Laxenburg, Austria

The World in 2050 (2020) A global research initiative in support of a successful implementation of the United Nations 2030 Agenda. Laxenburg, Austria

UN (2000) United Nations Millennium Declaration United Nations General Assembly. UNG Assembly, New York, p 9

UN (2015) Transforming our world: the 2030 Agenda for Sustainable Development. United Nations General Assembly, New York, p 35

UN (2016) Follow-up and review of the 2030 Agenda for Sustainable Development at the global level. United Nations General Assembly, New York, p 4

UN Statistics Division London Group on Environmental Accounting (2014) Towards a definition of Natural Capital. United Nations Statistics Division, London

UNEP (2010) IEA training manual: a training manual on integrated environmental assessment and reporting. UNEP and IISD, Nairobi

UNEP (2015) Policy coherence of the sustainable development goals: a natural resource perspective. United Nations Environment Programme, Paris

UNEP (2016) Healthy environment, healthy people. United Nations Environment Programme, Nairobi

United Nations Department of Economic and Social Affairs (2020) Global SDG indicators database. In: UN Statistics Division (ed)

UNSAB (2016) Indigenous and local knowledge(s) and science(s) for sustainable development. In: SC/2016/UNSAB/ILK. Scientific Advisory Board of the UN Secretary-General

van Soest HL, van Vuuren DP, Hilaire J, Minx JC, Harmsen MJHM, Krey V, Popp A, Riahi K, Luderer G (2019) Analysing interactions among sustainable development goals with integrated assessment models. Glob Transit 1:210-225. https://doi.org/10.1016/j. glt.2019.10.004 van Vuuren D, Kriegler E, Riahi K, Zimm C, Creutzig F, Goujon A, Grubler A, Hasegawa T, McCollum D, Muttarak R, Parkinson S, Scheelbeek P, Sellers S, Paula Aguiar A, Bhowmik A, Boza-Kiss B, Busch S, Campagnolo L, Collste D, Cornell S, Drombrowsky I, Ebi KL, Edelenbosch O, Edmonds J, Fujimori S, Haberl H, Häyhä T, Kamei M, Kolp P, Leininger J, Lotze-Campen H, Messner D, Murray K, Obersteiner M, Pachauri S, Popp A, Portugal Pereira J, Schaeffer R, Sempeho G, van Soest H, Wada Y (2018) Sustainable development pathways. In: Kriegler E, Messner D, Nakicenovic N, Riahi K, Rockström J, Sachs J, Leeuw SVD, van Vuuren D (eds) Transformations to achieve the Sustainable Development Goals: Report prepared by The World in 2050 initiative. International Institute for Applied Systems Analysis (IIASA), Laxenburg, pp 69-106

Waage J, Yap C, Bell S, Levy C, Mace G, Pegram T, Unterhalter E, Dasandi N, Hudson D, Kock R, Mayhew S, Marx C, Poole N (2015) Governing the UN sustainable development goals: interactions, infrastructures, and institutions. Lancet Glob Health 3:e251-e252. https://doi.org/10.1016/S2214-109X(15)70112-9

Weitz N, Nilsson M, Davis M (2015) A nexus approach to the post2015 agenda: formulating integrated water, energy, and food SDGs. SAIS Rev 34:37-50

Weitz N, Carlsen H, Nilsson M, Skånberg K (2018) Towards systemic and contextual priority setting for implementing the 2030 Agenda. Sustain Sci 13:531-548. https://doi.org/10.1007/s1162 5-017-0470-0

Publisher's Note Springer Nature remains neutral with regard to jurisdictional claims in published maps and institutional affiliations. 